(C) Elsevier Sequoia S.A., Lausanne - Printed in The Netherlands

\title{
A FARADAIC IMPEDANCE STUDY OF THE REDUCTION OF OXYGEN FROM AQUEOUS ALKALINE SOLUTION AT THE DROPPING MERCURY ELECTRODE
}

\author{
M.M.J. PIETERSE, M. SLUYTERS-REHBACH and J.H. SLUYTERS \\ Van 't Hoff Laboratory of Physical and Colloid Chemistry, State University, Padualaan 8, \\ Utrecht (The Netherlands)
}

(Received 9th July 1979; in revised form 1st September 1979)

\begin{abstract}
The reduction of oxygen to hydrogen peroxide at a dropping mercury electrode in an aqueous solution of $1 M \mathrm{KNO}_{3}+0.04 M \mathrm{KOH}(\mathrm{pH}=12.35)$ has been studied by means of impedance measurements as a function of frequency and d.c. potential. The reaction appears to be nearly reversible in the dc sense, but quasi-reversible in the ac sense. The impedance data obey the Randles' equivalent circuit with the following apparent values for the kinetic parameters: standard heterogeneous rate constant $k_{\mathrm{sh}}^{\mathrm{a}}=0.035 \mathrm{~cm} \mathrm{~s}^{-1}$ and cathodic transfer coefficient $\alpha_{c}^{\mathrm{a}}=0.22$. The results are interpreted in terms of a two-step charge transfer mechanism with the step $\mathrm{O}_{2}+e \rightleftharpoons \mathrm{O}_{2}^{-}$being rate-determining.
\end{abstract}

\section{INTRODUCTION}

The electrochemical reduction of oxygen has been the object of many fundamental studies, and is still recognized as an important matter of interest, e.g. in connection with fuel cell design and its role in biological processes.

In contrast to most other electrode materials, a mercury electrode offers the possibility to investigate the kinetics of the partial reduction of oxygen to hydrogen peroxide in aqueous solution, the total reduction to water, though thermodynamically prefered, evidently proceeding very irreversibly.

Jacq and Bloch [1] have designed a general reaction scheme, for the $\mathrm{O}_{2} / \mathrm{H}_{2} \mathrm{O}_{2}$ reaction, in terms of all the possible mono-electron transfer steps and the accompanying chemical protonation-deprotonation reaction steps. On the basis of what is known about relative thermodynamic stability of the participating species and additional considerations of the chemical reaction rates, it appears possible to predict the most probable pathways leading from $\mathrm{O}_{2}$ to $\mathrm{H}_{2} \mathrm{O}_{2}$ vice versa in acid medium and from $\mathrm{O}_{2}$ to $\mathrm{HO}_{2}^{-}$vice versa in alkaline medium. Thereupon the corresponding dc current-voltage expressions are derived, using Jacq's diffusion layer theory for coupled homogeneous chemical reactions [2]. By comparison of these theoretical results with experimental data (from dc polarograms) conclusions are drawn about the standard potentials and the standard heterogeneous rate constants of the two redox systems $\mathrm{O}_{2} / \mathrm{O}_{2}^{-}$and $\mathrm{O}_{2}^{-} / \mathrm{O}_{2}^{2-}$.

These results are in disagreement with the observations reported later by Chevalet et al. [3], who were able to obtain a polarographic wave due to the first reduction step $\mathrm{O}_{2} / \mathrm{O}_{2}^{-}$alone by adding the surfactant $\alpha$-quinoline which 
evidently inhibits the subsequent processes. Their conclusion is that the protonation of $\mathrm{O}_{2}^{-}$is a heterogeneous process occurring at the electrode surface.

In order to test a model for the reaction mechanism it could be useful to make a detailed analysis of the kinetic parameters of the electrode reaction. The faradaic impedance method is a useful technique for this purpose [4], especially when the overall rate of the electrode reaction is so large that the dc wave is found to be reversible, i.e. when it is impossible to calculate the kinetic parameters from dc data analysis [5]. For the oxygen/peroxide couple at mercury this is the case in alkaline medium, at $\mathrm{pH}>10[6,7]$. Moreover from impedance analysis it might be possible to detect the occurrence of accompanying homogeneous chemical reactions, since in that case a typical frequency dependence can be expected [8].

To our knowledge the only impedance study of the oxygen reduction at mercury published thus far is that of Moussa et al. [9]. The pH-range covered in this study is from 8.8 to 12.58 , but the kinetic analysis is restricted to measurements at one frequency $(1000 \mathrm{~Hz})$ and one potential (apparently the "peak potential" in the pseudo-capacitance vs. potential plot). From these data the apparent standard heterogeneous rate constant $k_{\text {sh }}^{2}$ is calculated using a theoretical relation, the significance of which is rather unclear. Though this procedure throws some doubt on the correctness and the accuracy of the results a substantial $\mathrm{pH}$-dependence of the rate constant is found.

The aim of the work presented in this paper is to extend the practical procedure, which implies the application of the frequency variation method at various potentials at both sides of the half-wave potential, in order to determine both the apparent rate constant and the transfer coefficient of the oxygenperoxide reaction at a rather high $\mathrm{pH}(\mathrm{pH}=12.35)$. The results will be discussed in relation to the references cited above and also in view of a study in a wider $\mathrm{pH}$ range which will be published later on [10].

\section{EXPERIMENTAL}

The ac measurements were performed with the automatic Network Analyzer system described elsewhere [11]. This system measures the cell impedance in terms of amplitude and phase angle at a given set of frequencies and dc potentials. The amplitude of the sine wave perturbation was chosen to be $10 \mathrm{mV}$ peak to peak. The a.c. measurement was carried out at a fixed time $(4.00 \mathrm{~s})$ after drop-birth, the moment of the preceding drop-fall being detected by a drop-fall detector [12].

The frequency range useful for analysis was found to be 70-3000 $\mathrm{Hz}(12$ frequencies) and the dc potential range was chosen from $-130 \mathrm{mV}$ to $-200 \mathrm{mV}$ vs. SCE. The corresponding dc polarogram was recorded manually, using a potentiostatic set-up.

Both dc and ac measurements were performed with a three-electrode cell, consisting of a dropping mercury electrode'(DME), a mercury pool counter electrode and a saturated calomel (SCE) reference electrode. The capillary for the DME was finely tapered and siliconized. The cell was kept at $25^{\circ} \mathrm{C}$.

The supporting electrolyte was prepared from analytical grade $\mathrm{KNO}_{3}(1 M)$ and $\mathrm{KOH}(0.04 \mathrm{M})$ in twice distilled water. The $\mathrm{pH}$ of this solution, measured 
with a Radiometer G 202 B glass electrode, was 12.35 .

The measurements were run both in deaerated and air saturated solutions. The concentration of oxygen in the latter was calculated by interpolation between literature data [13] of the solubility of oxygen in $\mathrm{KNO}_{3}$ solutions of different concentration. Assuming that the effect of $\mathrm{OH}^{-}$on the solubility does not differ much from the effect of $\mathrm{NO}_{3}^{-}$it can be concluded that the $\mathrm{O}_{2}$ concentration will be $0.2 \times 10^{-3} \mathrm{M}$.

It has been shown [11] that the slow response of the Network Analyzer to the time-dependent signal of the DME causes systematic errors in the measured amplitudes of ca $1.5 \%$. These errors have been accounted for in the ultimate calculations.

\section{THEORY}

As usual the impedance analysis starts from the real component $Y_{\mathrm{el}}^{\prime}$ and the imaginary component $Y_{\mathrm{el}}^{\prime \prime}$ of the interfacial admittance, which are computed from the raw impedance data after subtraction of the ohmic resistance.

If the rate of the electrode reaction is controlled only by diffusion and electron transfer (not complicated by the occurrence of stable intermediates or reactant adsorption) the interfacial admittance depends on frequency in the following manner [4]:

$$
\begin{aligned}
& Y_{\mathrm{el}}^{\prime}=\frac{\omega^{1 / 2}}{\sigma} \frac{p+1}{p^{2}+2 p+2} \\
& Y_{\mathrm{el}}^{\prime \prime}=\frac{\omega^{1 / 2}}{\sigma} \frac{1}{p^{2}+2 p+2}+\omega C_{\mathrm{d}} \\
& p=p^{\prime} \omega^{1 / 2}=\left(R_{\mathrm{ct}} / \sigma\right) \omega^{1 / 2}
\end{aligned}
$$

where $C_{\mathrm{d}}$ is the double-layer capacity of the electrode/electrolyte interface, $p$ the "irreversibility quotient", $\sigma$ the Warburg coefficient and $R_{\text {ct }}$ the charge transfer resistance. The values of these quantities are obtained by means of fitting to the $\omega^{1 / 2} / Y_{\mathrm{el}}^{\prime}$ vs. $\omega^{1 / 2}$ and/or $\left(Y_{\mathrm{el}}^{\prime \prime}-\omega C_{\mathrm{d}}\right) / \omega^{1 / 2}$ vs. $\omega^{1 / 2}$ plots [4].

The potential dependence of $R_{\mathrm{ct}}$ (in a former notation: $\theta$ ) and $\sigma$ has been expressed by the relations [4]:

$$
\begin{aligned}
& R_{\mathrm{ct}}=\frac{R T}{n^{2} F^{2} c_{\mathrm{O}}^{*}} \frac{1}{k_{\mathrm{sh}}} \frac{\left(a_{\mathrm{O}} / k_{\mathrm{sh}}\right) \exp \left(\alpha_{\mathrm{c}} \phi\right)+1+\left(a_{\mathrm{O}} / a_{\mathrm{R}}\right) \exp (\phi)}{\alpha_{\mathrm{c}}\left(a_{\mathrm{O}} / k_{\mathrm{sh}}\right)+\left(a_{\mathrm{O}} / a_{\mathrm{R}}\right) \exp \left(\alpha_{\mathrm{a}} \phi\right)} \\
& \sigma=\frac{R T}{n^{2} F^{2} c_{\mathrm{O}}^{*}\left(2 D_{\mathrm{O}}\right)^{1 / 2}} \frac{\left(a_{\mathrm{O}} / k_{\mathrm{sh}}\right) \exp \left(\alpha_{\mathrm{c}} \phi\right)+1+\left(a_{\mathrm{O}} / a_{\mathrm{R}}\right) \exp (\phi)}{\alpha_{\mathrm{c}}\left(a_{\mathrm{O}} / k_{\mathrm{sh}}\right)+\left(a_{\mathrm{O}} / a_{\mathrm{R}}\right) \exp \left(\alpha_{\mathrm{a}} \phi\right)} \\
& \quad \times\left[\exp \left(-\alpha_{\mathrm{c}} \phi\right)+\left(D_{\mathrm{O}} / D_{\mathrm{R}}\right)^{1 / 2} \exp \left(\alpha_{\mathrm{a}} \phi\right)\right] \\
& \phi=(n F / R T)\left(E-E^{0}\right) \\
& \alpha_{\mathrm{O}}=D_{\mathrm{O}} / \delta_{\mathrm{O}}, \quad \alpha_{\mathrm{R}}=D_{\mathrm{R}} / \delta_{\mathrm{R}}
\end{aligned}
$$


In these equations the dc mass transport is accounted for by the well-known diffusion layer model, which with $\delta_{\mathrm{i}}^{-1}=\left(3 \pi t D_{\mathrm{i}} / 7\right)^{-1 / 2}+r_{0}^{-1}$ is a good approximation in the case of a DME with radius $r_{0}[4,14]$. The charge transfer process is represented by the "standard heterogeneous rate constant" $k_{\mathrm{sh}}$ and the "cathodic and anodic transfer coefficients" $\alpha_{c}$ and $\alpha_{a}$, according to the ButlerVolmer expression for a simple electrode reaction $\mathrm{O}+n e^{-} \rightleftharpoons \mathrm{R}$. The bulk concentration of $\mathrm{O}$ is $c_{\mathrm{O}}^{*}$, while the bulk concentration of $\mathrm{R}$ is taken zero.

For the system of our interest it is necessary to consider the meaning of $E^{0}$ and $k_{\mathrm{sh}}$ with some care, because of two reasons:

(1) At $\mathrm{pH} 12.35$ the species $\mathrm{H}_{2} \mathrm{O}_{2}$ and its anion $\mathrm{HO}_{2}^{-}$exist simultaneously, in equilibrium.

(2) The reduction of $\mathrm{O}_{2}$ to $\mathrm{HO}_{2}^{-}$-involves a protonation step by which a hydroxyl ion is liberated.

So, the overall reaction is represented by

$\mathrm{O}_{2}+2 e^{-}+\mathrm{H}_{2} \mathrm{O} \rightleftharpoons \mathrm{HO}_{2}^{-}+\mathrm{OH}^{-}$

$\mathrm{HO}_{2}^{-}+\mathrm{H}_{2} \mathrm{O} \rightleftharpoons \mathrm{H}_{2} \mathrm{O}_{2}+\mathrm{OH}^{-}$

It is convenient to define the standard potential $E^{0}$ as that potential where, under Nernstian conditions, the surface concentrations are related by

$c_{\mathrm{O}}=c_{\mathrm{O}_{2}}=c_{\mathrm{HO}_{2}^{-}}+c_{\mathrm{H}_{2} \mathrm{O}_{2}}=c_{\mathrm{R}}$

This $E^{0}$ can be related, for instance, to the standard potential of reaction (8a) by

$E^{0}=E_{\mathrm{O}_{2} / \mathrm{HO}_{2}^{-}}^{0}+(R T / 2 F) \ln \left[1+1 /\left(K_{\mathrm{C}_{\mathrm{O}^{-}}}\right)\right]-(R T / 2 F) \ln c_{\mathrm{OH}^{-}}$

with

$K=c_{\mathrm{HO}_{2}^{-}} / c_{\mathrm{H}_{2} \mathrm{O}_{2}} c_{\mathrm{OH}^{-}}$

If care is taken to maintain the surface concentration $c_{\mathrm{OH}^{-}}$constant, a "Butler-Volmer like" rate equation can be postulated in the form

$$
\begin{aligned}
i & =n F\left[k_{\mathrm{b}} c_{\mathrm{R}}-k_{\mathrm{f}} c_{\mathrm{O}}\right] \\
& =n F k_{\mathrm{sh}}\left[c_{\mathrm{R}} \exp \left(\alpha_{\mathrm{a}} \phi\right)-c_{\mathrm{O}} \exp \left(-\alpha_{\mathrm{c}} \phi\right)\right]
\end{aligned}
$$

so that $k_{\mathrm{sh}} \exp \left(-\alpha_{\mathrm{c}} \phi\right)=k_{\mathrm{f}}$ is the forward rate constant at the potential $E$. In this conception eqs. (4) and (5) remain applicable.

$N . B$. : Note that using concentrations instead of activities implies that activity coefficients are incorporated in $E^{0}, K$ and/or $k_{\mathrm{sh}}$.

Equations (4) and (5) can be largely simplified in the case of "dc reversible" behavior, which in theories of ac polarography is said to occur if the influences of charge transfer and of sphericity of the electrode on the dc process are negligible [14]. It is convenient then to introduce the reversible half-wave potential $E_{1 / 2}^{\mathrm{r}}=E^{0}+(R T / n F) \ln \left(D_{\mathrm{R}} / D_{\mathrm{o}}\right)^{1 / 2}$, which with $d=\left(D_{\mathrm{O}} / D_{\mathrm{R}}\right)^{1 / 2}$ leads to

$R_{\mathrm{ct}, \mathrm{rev}}=\frac{R T}{n^{2} F^{2} c_{\mathrm{o}}^{*}} \frac{\exp \left(\alpha_{\mathrm{c}} j\right)}{d^{\alpha} k_{\mathrm{sh}}} \frac{[1+\exp (j)]}{\exp (j)}$ 
$\sigma_{\mathrm{rev}}=\frac{R T}{n^{2} F^{2} c_{\mathrm{O}}^{*}\left(2 D_{\mathrm{O}}\right)^{1 / 2}} \frac{[1+\exp (j)]^{2}}{\exp (j)}$

$j=(n F / R T)\left(E-E_{1 / 2}^{\mathrm{r}}\right)=\phi+\ln \left(D_{\mathrm{O}} / D_{\mathrm{R}}\right)^{1 / 2}$

For comparison [see also Discussion] we rewrite eqs. (4) and (5) in terms of $\exp (j)$ :

$R_{\mathrm{ct}}=\frac{R T}{n^{2} F^{2} c_{\mathrm{O}}^{*}} \frac{\exp \left(\alpha_{\mathrm{c}} j\right)}{d^{\alpha_{\mathrm{c}}} k_{\mathrm{sh}}} \frac{\left(a_{\mathrm{o}} / d^{\alpha} k_{\mathrm{sh}}\right) \exp \left(\alpha_{c} j\right)+1+r_{\mathrm{s}} \exp (j)}{\alpha_{\mathrm{c}}\left(a_{\mathrm{o}} / d^{\alpha} k_{\mathrm{sh}}\right) \exp \left(\alpha_{\mathrm{c}} j\right)+r_{\mathrm{s}} \exp (j)}$

$\sigma=\frac{R T}{n^{2} F^{2} c_{\mathrm{o}}^{*}\left(2 D_{\mathrm{O}}\right)^{1 / 2}} \frac{\left(a_{\mathrm{o}} / d^{\alpha_{\mathrm{c}}} k_{\mathrm{sh}}\right) \exp \left(\alpha_{\mathrm{c}} j\right)+1+r_{\mathrm{s}} \exp (j)}{a_{\mathrm{c}}\left(a_{\mathrm{o}} / d^{\alpha_{c}} k_{\mathrm{sh}}\right) \exp \left(\alpha_{\mathrm{c}} j\right)+r_{\mathrm{s}} \exp (j)}[1+\exp (j)]$

where $d=\left(D_{\mathrm{O}} / D_{\mathrm{R}}\right)^{1 / 2}$ and $r_{\mathrm{s}}$ is a factor caused by sphericity:

$r_{\mathrm{s}}=\frac{r_{0}+\left(3 \pi t D_{\mathrm{O}} / 7\right)^{1 / 2}}{r_{0}+\left(3 \pi t D_{\mathrm{R}} / 7\right)^{1 / 2}}$

\section{RESULTS}

From the limiting current of the dc polarogram the diffusion coefficient $D_{0}$ of oxygen was calculated using the Ilkovič equation corrected for spherical diffusion [15]. The result is $D_{\mathrm{o}}=2.3 \times 10^{-5} \mathrm{~cm}^{2} \mathrm{~s}^{-1}$. The $\log \left[\left(I_{\mathrm{d}}-I\right) / I\right]$ vs. $E$ plot analysis yields a straight line with nearly a reversible slope $\left[32 \mathrm{mV}^{-1}\right]$, from which the dc half-wave potential $E_{1 / 2}=-168 \mathrm{mV}$ vs. SCE is calculated.

The diffusion coefficient $D_{\mathrm{R}}$ of hydrogen peroxide is $1.2 \times 10^{-5} \mathrm{~cm}^{2} \mathrm{~s}^{-1}$ [16] at this $\mathrm{pH}$ value. The value of $r_{\mathrm{s}}$, calculated from $D_{\mathrm{O}}, D_{\mathrm{R}}$ and the capillary characteristics, is $r_{\mathrm{s}}=1.04$.

After transformation of the impedance measurements into the interfacial

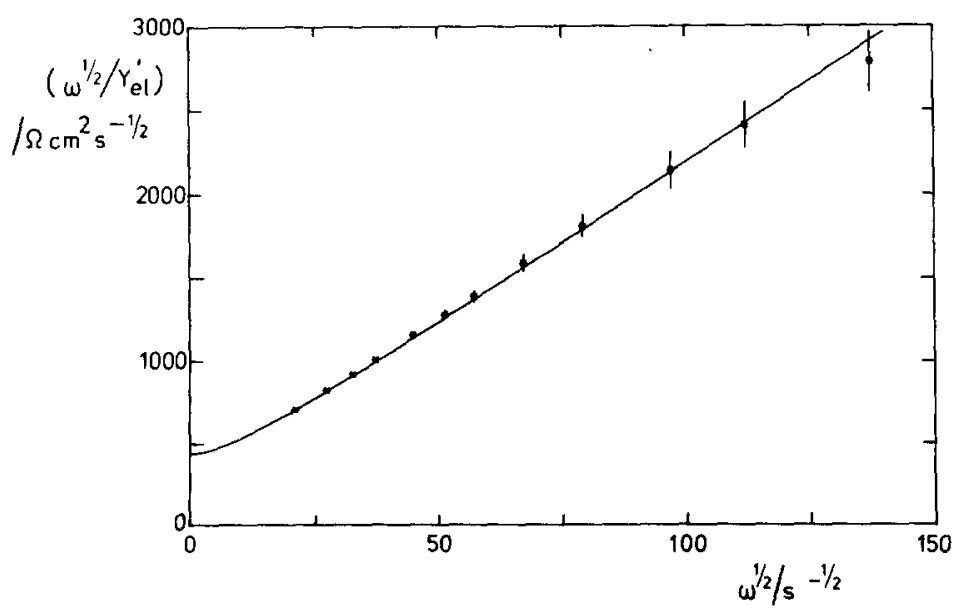

Fig. 1. The experimental points and the theoretical $\omega^{1 / 2} / Y_{\mathrm{el}}^{\prime}$ vs. $\omega^{1 / 2}$ curve, calculated for $p^{\prime}=0.089 \mathrm{~s}^{1 / 2}$ and $\sigma=219 \Omega \mathrm{cm}^{2} \mathrm{~s}^{-1 / 2}$ at $-170 \mathrm{mV}$, for an air-saturated $1 M \mathrm{KNO}_{3}+\mathrm{KOH}$ solution $(\mathrm{pH}=12.35)$ at the DME. 

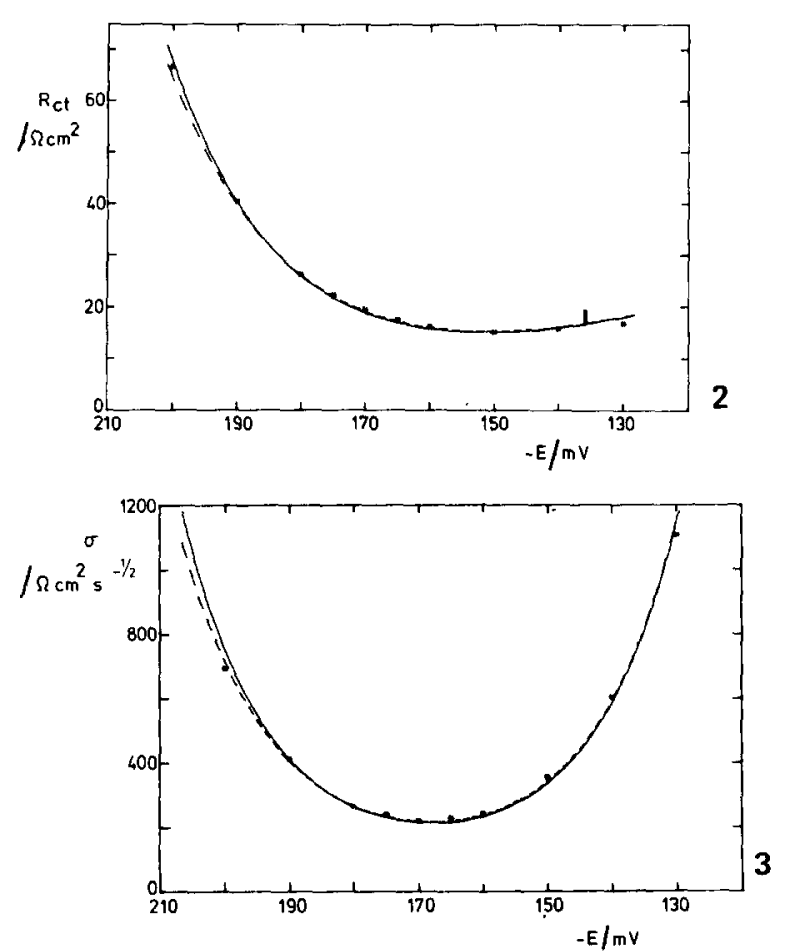

Figs. 2 and 3 . The charge transfer resistance $R_{\text {ct }}$ (upper) and the Warburg coefficient $\sigma$ as a function of potential for an air-saturated $1 \mathrm{MKNO}_{3}+\mathrm{KOH}$ solution $(\mathrm{pH}=12.35)$ at the DME. Theoretical curves are calculated according to the general eqs. (16) and (17) (dashed lines) and the "reversible" eqs. (13) and (14) (solid lines).

admittance plots were prepared of $\omega^{1 / 2} / Y_{\mathrm{el}}^{\prime} \mathrm{vs}, \omega^{1 / 2}$. A typical example is shown in Fig. 1. The observed increase with frequency is in accordance with the function expressed by eqn. (1) and is indicative for the presence of both charge transfer and diffusion control [4].

The experimental errors indicated in Fig. 1 by the vertical bars were estimated by replacing the cell by a dummy cell of approximately the same impedance $(R-C$ series connection) and determining the deviations between the measured impedance components and the theoretical ones. It can be seen that the in-phase admittance satisfactorily obeys eqn. (1) with values for $\alpha$ and $p^{\prime}$ computed by a fitting procedure. Similar results were obtained at the other potentials. As a check on consistency the $\sigma$ and $p^{\prime}$ values were substituted into eqn. (2), together with the experimental $Y_{\mathrm{el}}^{\prime \prime}$ values, to yield the double-layer capacity $C_{\mathrm{d}}$. The obtained $C_{\mathrm{d}}$ values are within experimental error equal to those measured in the supporting electrolyte, at the same potential but in the absence of oxygen. It can be concluded that the conditions for eqns. (1)-(3) are fulfilled, i.e. "Randles behaviour" previals.

The experimental results for $R_{\mathrm{ct}}=\sigma p^{\prime}$ [eqn. (3)] and $\sigma$ are shown in Figs. 2 and 3 respectively. The data appear to be in very good agreement with theoretical curves calculated with eqns. (16) and (17) after substitution of the following values for the parameters: $E_{1 / 2}=-168 \mathrm{mV}$ vs. SCE, $c_{\mathrm{O}}^{*}=0.20 \times 10^{-6} \mathrm{~mol}$ 
$\mathrm{cm}^{-3}, D_{\mathrm{O}}=1.9 \times 10^{-5} \mathrm{~cm}^{2} \mathrm{~s}^{-1}, D_{\mathrm{R}}=1.2 \times 10^{-5} \mathrm{~cm}^{2} \mathrm{~s}^{-1}, \alpha_{\mathrm{c}}=1-\alpha_{\mathrm{a}}=0.22$, $k_{\mathrm{sh}}=0.035 \mathrm{~cm} \mathrm{~s}^{-1}$. These theoretical curves are represented by the dashed lines, whereas the solid lines represent the "reversible" curves according to eqns. (13) and (14) with the same parameter values.

\section{DISCUSSION}

The diffusion coefficient of $\mathrm{O}_{2}$

The dc polarogram and the impedance data yield significantly different values for the diffusion coefficient of oxygen in our supporting electrolyte, namely: $D_{\mathrm{O}_{2}}=(2.3 \pm 0.1) \times 10^{-5} \mathrm{~cm}^{2} \mathrm{~s}^{-1}$ from the dc polarogram $D_{\mathrm{O}_{2}}=(1.9 \pm 0.1) \times 10^{-5} \mathrm{~cm}^{2} \mathrm{~s}^{-1}$ from the Warburg coefficient

Literature data for the diffusion coefficient of $\mathrm{O}_{2}$ in $1 M \mathrm{KNO}_{3}$ solution could not be found. Recent studies by Davis et al. [17] and Gubbins and Walker [18] on the diffusivity of oxygen in aqueous $\mathrm{KOH}$ solutions report amongst other the values $D_{\mathrm{O}_{2}}=1.4 \times 10^{-5} \mathrm{~cm}^{2} \mathrm{~s}^{-1}$ [17] resp. $D_{\mathrm{O}_{2}}=1.6 \times 10^{-5} \mathrm{~cm}^{2} \mathrm{~s}^{-1}[18]$ for $1 M \mathrm{KOH}$, and the extrapolated value for pure water: $D_{\mathrm{O}_{2}}^{\infty}=1.9 \times 10^{-5} \mathrm{~cm}^{2}$ $\mathrm{s}^{-1}[17,18]$.

Since the diffusing particle is uncharged and most probably has the radius of the monohydrated oxygen molecule [19], it is allowed to compare these data via the Stokes-Einstein law:

$\eta D=k T / 6 \pi r=\mathrm{constant}$

where $\eta$ is the relative viscosity [20]. For the data above we have with corresponding values for $\eta[21]$ :

pure water:

$$
\eta D_{\mathrm{O}_{2}}=1.9 \times 10^{-5} \mathrm{~cm}^{2} \mathrm{~s}^{-1} \text { (by definition) }
$$

$1 M \mathrm{KOH}$ :

$$
\begin{aligned}
& \eta D_{\mathrm{o}_{2}}=1.58 \times 10^{-5} \mathrm{~cm}^{2} \mathrm{~s}^{-1} \text { (ref. 17) } \\
& \eta D_{\mathrm{o}_{2}}=1.81 \times 10^{-5} \mathrm{~cm}^{2} \mathrm{~s}^{-1} \text { (ref. 18) }
\end{aligned}
$$

$1 M \mathrm{KNO}_{3} / 0.04 M \mathrm{KOH}: \quad \eta D_{\mathrm{O}_{2}}=1.83 \times 10^{-5} \mathrm{~cm}^{2} \mathrm{~s}^{-1}$ (from ac data)

$$
\eta D_{\mathrm{O}_{2}}=2.21 \times 10^{-5} \mathrm{~cm}^{2} \mathrm{~s}^{-1} \text { (from dc polarogram) }
$$

With some care it can be concluded that the $D_{\mathrm{O}_{2}}$ value derived from the ac data appears to be the more reliable one. It is not clear as yet why the dc value is so much higher, the difference being $10 \%$ in $\sqrt{D_{\mathrm{O}_{2}}}$.

\section{The rate constant and the question of reversibility}

As can be seen in Fig. 3, the potential dependence of the Warburg coefficient is slightly better described by the general eqn. (17) than the "reversible" eqn. (14). This can be visualized by calculating the factor $F(t)$ introduced by Smith et al. [14] as the factor accounting for deviation from dc reversible behaviour in the ac polarographic current. In our notation of the admittance representation it is easily shown [4] that

$F(t)=\sigma_{\mathrm{rev}} / \sigma_{\mathrm{irr}}=R_{\mathrm{ct}, \mathrm{rev}} / R_{\mathrm{ct}, \mathrm{irr}}$

The potential dependence of $F(t)$ in the present case is shown in Fig. 4. It may 


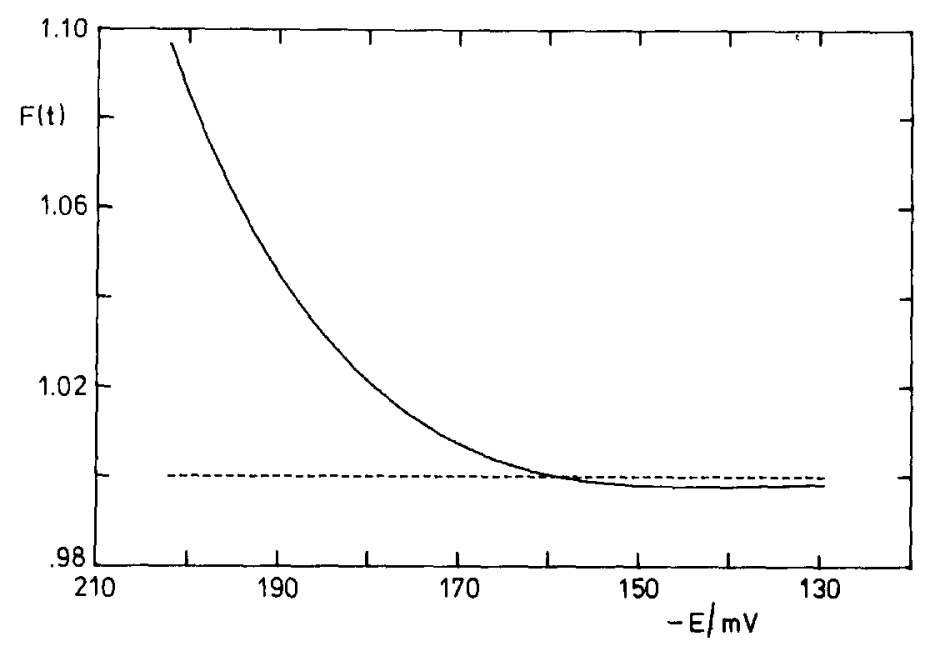

Fig. 4. The influence of the irreversibility and the sphericity $F(t)$ as a function of the potential.

be noted that both the irreversibility and the sphericity play a role in the deviation from the "reversible behaviour". At extreme negative potentials these effects enhance each other, but around the half-wave potential (from -180 to $-150 \mathrm{mV}$ ) the effects are counteracting. The whole deviation becomes negligible (i.e., $F(t) \approx 1$ ) at the most positive potentials, -140 and $-130 \mathrm{mV}$. Note that near the half-wave potential the effect due to sphericity counteracts the effect due to irreversibility, so that apparently the experimental minimum $\sigma$-value is equal to the theoretical "reversible" value.

The value of the apparent rate constant, $k_{\mathrm{sh}}^{\mathrm{a}}=0.035 \mathrm{~cm} \mathrm{~s}^{-1}$, obtained from our measurements, at first sight fits reasonably well in the series of values reported by Moussa et al. [9] for the $\mathrm{pH}$ range 8,8-12.17: $k_{\mathrm{sh}}^{\mathrm{a}}=0.015-0.052$ $\mathrm{cm} \mathrm{s}^{-1}$ (the authors do not give any explanation to the much higher value, $k_{\mathrm{sh}}^{\mathrm{a}}=$ 0.474 , obtained at $\mathrm{pH}=12.58$ ). However, their calculation of the rate constant appears to be based on an erroneous equation for the quantity $R_{\mathrm{r}}-1 / \omega C_{\mathrm{r}}$, which in our notation must be equal to the transfer resistance $R_{\mathrm{ct}}$. The equation used is the one originally given by Randles [22], but this equation holds for a transfer resistance measured at the equilibrium potential for the case that both $\mathrm{Ox}$ and Red are initially present in equal concentrations, $c_{\mathrm{O}}^{*}=c_{\mathrm{R}}^{*}$. Roughly, the value for $R_{\mathrm{ct}}$ near the half-wave potential with $c_{\mathrm{R}}^{*}=0$, will be twice as large, which implies that the resulting rate constant at $\mathrm{pH}=12.17$ will be ca. $0.1 \mathrm{~cm}$ $\mathrm{s}^{-1}$. So, in reality the difference from our result is larger. A possible explanation can be found in the different choice of the supporting anion, $1 M \mathrm{~F}^{-}$in Moussa's case and $1 \mathrm{M} \mathrm{NO}_{3}^{-}$in our case. Due to the different degree of specific adsorption the Frumkin effect will be different in the two media [7].

The transfer coefficients and the reaction mechanism

Devanathan [23] has derived theoretical values for the true overall transfer coefficients - i.e., after correction for the Frumkin effect - for multi-electron 
transfer, which takes place via a succession of $\mathbf{n}$ steps involving a single electron transfer each. The assumptions are: (a) the transfer coefficient equals 0.5 for each individual one-electron step; (b) the (unstable) intermediates are involved neither in rate-determining chemical reactions nor in adsorption processes; (c) one step in the whole sequence is rate-determining. For a two-electron reaction

$\mathrm{O}+e^{-} \rightleftharpoons \mathrm{Y} \quad$ 1st step

$\mathrm{Y}+e^{-} \rightleftharpoons \mathrm{R} \quad$ 2nd step

one has

$\alpha_{\mathrm{a}}=0.75$ and $\alpha_{\mathrm{c}}=0.25$ if the first step is rate determining,

$\alpha_{\mathrm{a}}=0.25$ and $\alpha_{\mathrm{c}}=0.75$ if the second step is rate-determining.

In view of this theory one could interpret our result, $\alpha_{c}=0.22$, as evidence for the mechanism

$$
\begin{array}{ll}
\mathrm{O}_{2}+e^{-} \rightleftharpoons \mathrm{O}_{2}^{-} & \text {1st step } \\
\mathrm{O}_{2}^{-}+\mathrm{H}_{2} \mathrm{O}+e^{-} \rightleftharpoons \mathrm{HO}_{2}^{-}+\mathrm{OH}^{-} & \text {2nd step }
\end{array}
$$

with the first step rate-determining. This is likely to confirm the speculations of other authors, e.g. of Chevalet et al. [3]. These authors were able to study the first step separately by d.c. polarography, after addition of $\alpha$-quinoline which evidently prevents the second step from proceeding. From their experiments they concluded that the protons needed to form $\mathrm{HO}_{2}^{-}$is donated by adsorbed water molecules, i.e. in a heterogeneous chemical reaction. This contradicts the theory of Jacq and Block [1], which implies that the protonation reactions occur somewhere in the solution.

Our impedance analysis supports the former view, because the frequency dependence is in agreement with Randles' behaviour and does not show any effect of accompanying chemical reactions.

It may be interesting to compare our value for the rate constant with the rate constants of the first step predicted in literature. To this end we make use of the detailed considerations of Van der Pol et al. [24], where it is shown that if the first step is rate-determining $k_{\mathrm{sh}}$ is to be interpreted as

$k_{\mathrm{sh}}=k_{\mathrm{sh} 1} \exp \left[-\alpha_{\mathrm{c} 1}\left(E^{0}-E_{1}^{0}\right) F / R T\right]$

where $k_{\text {sh } 1}$ is the standard heterogeneous constant of the first step, pertaining to the standard potential $E_{1}^{0}$ of the first step. Chevalet et al. [3] report the value $E_{1}^{0}=-355 \mathrm{mV}$ vs. SCE. With $E^{0}=-168 \mathrm{mV}$ vs. SCE, $k_{\mathrm{sh}}=0.035 \mathrm{~cm} \mathrm{~s}^{-1}$ and $\alpha_{\mathrm{c1}}=0.5$ we obtain $k_{\mathrm{sh} 1}=1.34 \mathrm{~cm} \mathrm{~s}^{-1}$.

This is in remarkable agreement with the value estimated by Jacq and Bloch [1], from otherwise quite different considerations. The value determined by Chevalet et al. [3], ca. $1.5 \times 10^{-3} \mathrm{~cm} \mathrm{~s}^{-1}$, is much lower. This could suggest that the added $\alpha$-quinoline also slows down the rate of the first charge transfer.

The question remains what the mechanism could be of the second step, which involves both protonation and electron transfer. It is conceivable that studies of the type presented here as a function of $\mathrm{pH}$ can be useful to answer this question. We intend to deal with this subject in a subsequent paper to be published in the near future.

Finally, in the discussion of the choice of a reaction mechanism theoretical 
arguments could be advanced. For instance on quantum-mechanical grounds the direct two-electron reduction of the ground state triplet $\mathrm{O}_{2}$ molecule with a singlet reductant to give singlet products, though thermodynamically highly favoured, is a spin forbidden process. On the other hand reaction of the triplet with a singlet to give two doublets is spin allowed. This could explain why the formation of superoxyde by one-electron reduction of $\mathrm{O}_{2}$ is kinetically favoured.

These types of arguments strictly are only valid in case of isolated molecules and the question remains whether it is allowed to apply them to aqueous solutions where interactions with the solvent molecules certainly will interfere.

\section{ACKNOWLEDGEMENTS}

The authors wish to express their gratitude to Drs. C.P.M. Bongenaar for his assistance during the impedance measurements.

\section{REFERENCES}

1 J. Jacq and O. Bloch, Electrochim. Acta, 15 (1970) 1945.

2 J. Jacq, Electrochim. Acta, 12 (1967) 1, 1345.

3 J. Chevalet, F. Rouelle, L. Gierst and J.P. Lambert, J. Electroanal. Chem., 39 (1972) 201.

4 M. Sluyters-Rehbach and J.H. Sluyters in A.J. Bard (Ed.), Electroanalytical Chemistry, Vol. 4, Marcel Dekker, New York, 1970.

5 J. Heyrovský and J. Kůta, Principles of Polarography, Academic Press, New York, 1966, p. 215.

6 K.J. Vetter, Electrochemical Kinetics, Academic Press, New York, 1967, p. 634.

7 J. Küta and J. Koryta, Coll. Czech. Chem. Commun., 30 (1965) 4095.

8 M. Sluyters-Rehbach and J.H. Sluyters, J. Electroanal. Chem., 26 (1970) 237.

9 A.A. Moussa, E.A. Radwan and H.A. Ghaly, Electrochim. Acta, 16 (1971) 1369.

10 M. Sluyters-Rehbach, M. Winters, A.G. Remijnse and J.H. Sluyters, to be submitted.

11 C.P.M. Bongenaar, M. Sluyters-Rebach and J.H. Sluyters, submitted.

12 Ch. Yarnitzky, C.A. Wijnhorst. B. v.d. Laar, H. Reyn and J.H. Sluyters, J. Electroanal. Chem., 77 (1977) 391.

13 C.G. Mac Arthur, J. Phys. Chem., 20 (1915/16) 495.

14 J.R. Delmastro and D.E. Smith, J. Electroanal. Chem., 9 (1965) 192.

15 J. Newman, J. Electroanal. Chem., 15 (1967) 309.

16 K. Kikuchi and T. Murayama, Bull. Chem. Soc., 49 (1976) 1554.

17 R.E. Davis, G.L. Horvath and C.W. Tobias, Electrochim. Acta, 12 (1967) 287.

18 K.E. Gubbins and R.D. Walkex Jr., J. Electrochem. Soc., 112 (1965) 469.

19 R.B. Heslop and P.L. Robinson, Inorganic Chemistry, Elsevier, Amsterdam, 1967, p. 473.

20 J. Heyrovský and J. Kůta, Principles of Polarography, Academic Press, New York, 1966, p. 105.

21 R.C. Weast (Ed.), Handbook of Chemistry and Physics, The Chemical Rubber Co., Cleveland, OH, 1971-72, D-206.

22 J.E.B. Randles, Discuss. Faraday Soc., 1 (1947) 11.

23 M.A.V. Devanathan, Electrochim. Acta, 17 (1972) 1683.

24 F. van der Pol, M. Sluyters-Rehbach and J.H. Sluyters, J. Electroanal, Chem., 58 (1975) 177. 